\title{
Chants des minorités des Hauts Plateaux du Nord
}

\section{Vietnam}

Enregistrements (1993) et texte trilingue (français-anglais-allemand) de Patrick Kersalé, 1995

\section{Trân Quang Hai}

\section{(2) OpenEdition}

\section{Journals}

Édition électronique

URL : http://journals.openedition.org/ethnomusicologie/1327

ISSN : 2235-7688

Éditeur

ADEM - Ateliers d'ethnomusicologie

Édition imprimée

Date de publication : 1 décembre 1996

Pagination : 365-366

ISBN : 978-2-8257-0559-9

ISSN : $1662-372 X$

\section{Référence électronique}

Trân Quang Hai, "Chants des minorités des Hauts Plateaux du Nord Vietnam », Cahiers

d'ethnomusicologie [En ligne], 9 | 1996, mis en ligne le 05 janvier 2012, consulté le 04 mai 2019. URL : http://journals.openedition.org/ethnomusicologie/1327

Ce document a été généré automatiquement le 4 mai 2019.

Tous droits réservés 


\section{Chants des minorités des Hauts Plateaux du Nord Vietnam}

Enregistrements (1993) et texte trilingue (français-anglais-allemand) de Patrick Kersalé, 1995

\section{Trân Quang Hai}

\section{RÉFÉRENCE}

Chants des minorités des Hauts Plateaux du Nord Vietnam. Enregistrements (1993) et texte trilingue (français-anglais-allemand) de Patrick Kersalé; photographies de Christine Garand. 1 CD VDE-Gallo/Peoples PEO CD-826, 1995. (42'30").

1 Jusqu'à présent on peut trouver plusieurs disques sur la musique de cour, la musique de chambre et la musique de théâtre du Viêt Nam, principalement produits, en tant que collecteurs ou interprètes, par Trân Van Khê et l'auteur de ces lignes. Un disque sur la musique des Mnong Gar, montagnards du Centre Viêt Nam, a jadis été édité par Ocora à partir d'enregistrements de Georges Condominas, mais c'est à ma connaissance la première fois qu'un disque sur la musique des minorités du Nord Viêt Nam est publié en Europe. Patrick Kersalé s'y est rendu pour enregistrer la magnifique musique vocale et instrumentale de quelques ethnies telles que Nung An, Yao Rouges, Hmong, et Thai Noirs.

2 Les Nung An attirent tout particulièrement notre attention. Les chants diaphoniques alternés entre garçons et filles ont révélé un aspect polyphonique extrêmement intéressant, par certains aspects similaire à celui pratiqué par les Bulgares. Une voix tient le bourdon, tandis que la deuxième se promène entre la tonique et la quinte en passant par des quartes, tierces et secondes, ce qui donne des intervalles consonants et dissonants. Les autres ethnies (Thai noirs, Yao rouges et Hmong) ne présentent pour leur part pas de révélations frappantes.

3 Le texte contient des informations sommaires sur l'analyse des pièces et la vie musicale de ces peuples. Malgré tout, c'est un disque intéressant, qui révèle une diaphonie vocale particulière au peuple Nung An, jamais traitée ni mentionnée par des chercheurs 
vietnamiens ou des missionnaires à l'époque coloniale. Signalons toutefois le $\mathrm{CD}$ publié en 1994 aux Etats-Unis par le Minnesota Composers Forum à partir des les documents sonores recueillis par Philip Blackburn et intitulé Stilling Time. Traditional Musics of Vietnam (CD INNOVA 112, 1994), qui contient notamment trois chants nùng, deux chants hmong, trois chants tày et deux chants yao rouges. 